\title{
Massage Therapy Usage and Reported Health in Older Adults Experiencing Persistent Pain
}

\author{
Niki Munk, PhD, LMT, Tina Kruger, BA, BS, and Faika Zanjani, PhD
}

\begin{abstract}
Background: Persistent pain is a frequent complaint among older adults and can greatly decrease quality of life while also contributing to other negative outcomes such as poor health, increased pharmaceutical medication usage, increased rates of depression, and cognitive decline.

Objective: The current study $(N=69)$ examines the potential impact of massage therapy (MT) in older adults $(60+$ years) with persistent pain, by comparing self-reported health outcome scores among those who have and have not utilized massage therapy in the past year.

Design: The current study was derived from a larger study that collected data as part of a one-time, self-report, mail-in survey.

Participants: Lexington, Kentucky area adults, 60 and older who reported persistent pain were eligible to participate in the study.

Outcome measures: The RAND 36-Item Health Survey was used to determine participant health-related quality of life.

Results: The current study demonstrated that for older adults experiencing persistent pain, massage is associated with self-report of less limitation due to physical or emotional issues, better emotional health, more energy/ less fatigue, better social functioning, and better overall health. Age, education, cumulative morbidities, number of areas in which participants reported experiencing persistent pain, and number of complementary and alternative medicine options in addition to MT utilized in the past year did not affect the association between receipt of massage and better self-reports in those domains.

Conclusions: While many causes of pain for older adults elude cure, further study is warranted that examines MT as an intervention to improve coping in older adults with persistent pain.
\end{abstract}

\section{Introduction}

$\mathbf{P}$ ERSISTENT PAIN (PP) is a frequent complaint of older adults. ${ }^{1}$ Negative outcomes associated with PP include poor health, ${ }^{2}$ depression, ${ }^{3,4}$ cognitive decline, ${ }^{5}$ and higher usage of pharmaceuticals. ${ }^{6}$ The phrase "persistent pain" is often used interchangeably with "chronic pain"; however, the negative connotation associated with "chronic pain" has led to increased use of the phrase "persistent pain. ${ }^{17}$ PP refers to a painful experience that "continues for a prolonged period of time and may or may not be associated with a well-defined disease process." 7 , p. 1331

High rates of persistent and acute pain have been reported by users of complementary and alternative medicine ${ }^{8-12}$ (CAM) including recipients of massage therapy ${ }^{13,14}$ (MT), with pain being the primary reason some adults utilize CAM treatments. ${ }^{13,15}$ While several studies demonstrate the posi- tive effects of MT on back pain, ${ }^{16,17}$ carpal tunnel syndrome, ${ }^{18}$ arthritis, ${ }^{19}$ and other pain-related conditions, ${ }^{20-23}$ few studies investigating pain focus specifically on older adults. $^{24}$ Due to the changes that accompany aging (e.g., decreases in metabolism, muscle mass, resistance, and resilience ${ }^{25,26}$ ), it is impossible to generalize results from MT studies that target younger adults to the older adult population.

Several books discuss the effects of massage and considerations for older adults, ${ }^{27-30}$ establishing a base of knowledge upon which scientific evidence has begun to build. While studies focusing on older adults exist in the MT research literature, $^{24,31-33}$ their numbers are few compared to other population subsets, and the studies are often limited by small sample sizes. Due to the limited existence of evidence-based studies, the benefits of MT are not well understood for older adults, especially regarding pain. Considering age-related

Graduate Center for Gerontology, University of Kentucky, Lexington, KY. 
decrements in health and function, ${ }^{34}$ studies examining the benefits of MT in older adults are necessary to determine the extent to which massage could serve as an effective, nonpharmaceutical approach to addressing gerontological health concerns, including PP. To that end, the authors performed exploratory data analysis on data collected in a previous study. ${ }^{35}$ The current study was conducted to examine the relationship between MT usage and reported health or quality of life among older adults who experience PP. To the best of the authors' knowledge, this is the first study to examine that relationship. As an exploratory study, the work presented here serves as a foundation for future research examining causal mechanisms among these variables.

This study specifically seeks to examine the relationship between self-reported health among older adults experiencing PP who have and have not utilized MT over the past year (MT usage status [MTUS]). In order to examine this relationship, the current study (1) compares demographic characteristics across MTUS, (2) compares self-reported health across MTUS, and (3) discusses the relationship between MTUS and differences in the health domain scores considered in this study. The last aim introduces a translational perspective by linking study findings to important qualityof-life issues among older adults. It is hypothesized that (1) older adults experiencing PP who received MT in the past year will have higher income and more education than those who reported not receiving MT; (2) self-reported health will be better for older adults experiencing PP who utilized MT in the past year; and (3) differences in self-reported health for older adults experiencing PP across MTUS will not be affected by potentially confounding factors such as age, education, pain descriptors (i.e., self-report of back pain or arthritis), and usage of other CAM options.

\section{Methods}

The current study was derived from a larger study examining the reported health of older adults across MTUS, regardless of self-reported PP. ${ }^{35}$ Data for this study were collected as part of a one-time, self-report, mail-in survey eliciting responses regarding demographics, personal health, health behaviors, CAM usage, and MT practices and behaviors. No identifying information was collected. The Office of Research Integrity at the University of Kentucky provided institutional review board review and approval all study procedures.

\section{Participants}

Participants were included in the original study if they were 60 years old or older and from the Lexington, Kentucky area. Participants either came from a mailing to 500 randomly selected, Fayette County registered voters, or from surveys distributed at MT clinics in the Lexington area to interested patrons. Random number generation was used to select a subset of 500 who were mailed a survey packet, out of the over 30,000 registered voters aged 60 and older in Fayette County Kentucky in 2007. Of that 500, 106 returned valid surveys. In addition, to ensure statistically adequate responses from older adults who received MT in the past year, 100 surveys were distributed to MT clinics in the Lexington area, of which 38 valid surveys were returned for a total of 144 surveys included in the original study. ${ }^{35}$ Of the
144 participants in that study, 69 (48 from voter registration list, 21 from clinic surveys) reported currently experiencing PP (i.e., answered "yes" to the question, "Do you currently experience persistent pain?"), and comprise the sample of the current study.

\section{Measures}

The survey used in the current study was developed and piloted specifically for the purposes of preliminary data collection and is described elsewhere. ${ }^{35}$ Responses to the RAND 36-Item Health Survey 1.0 $0^{36-37}$ (RAND-36) were used as outcomes variables for this study. The RAND-36 is a wellvalidated, health-related quality-of-life measure that produces a score for nine domains: perceived change in health, physical functioning, bodily pain, role limitations due to physical issues, emotional well-being, role limitations due to emotional/personal problems, social functioning, energy/ fatigue, and general health. Higher scores indicate better selfreported health.

\section{Variables and coding}

As no criteria are established in the literature to delineate whether a person is a MT user, previous survey studies of CAM usage and the American Massage Therapy Association (AMTA) Industry Facts Sheets were looked to for guidance in determining who should be considered massage users for this study. Although the AMTA occasionally reports users as those who have received MT in the fast 5 years, AMTA more often reports those who have utilized MT in the past 12 months, ${ }^{38,39}$ and previous CAM studies ask participants what therapies were utilized over the past year. $9,10,40,41$ Therefore, MTUS was categorized as a dichotomous variable based on participants' indication that they received MT in the past year (coded "yes" for MTUS) or did not (i.e., those who reported "ever" and "no" were coded as "no" for MTUS).

A cumulative morbidity variable was created and coded as continuous. Respondents were asked to indicate whether they had been diagnosed by a physician with any of the following: arthritis, fibromyalgia, hypertension, depression, heart disease or stroke, diabetes, respiratory disorder, thyroid disorder, renal disease, Parkinson disease, Alzheimer disease, and/or gastrointestinal disorders. Cumulative morbidity was the count of indicated conditions.

To better understand the pain experienced by participants, we asked about types of pain and in which areas of their body they experienced pain. Arthritis ${ }^{42,43}$ and back pain ${ }^{44}$ are prevalent conditions among older adults, so participants were asked whether or not they experienced either and both were included as dichotomous variables to characterize type of pain (listed under "pain descriptors" in Table 1). A "cumulative pain areas" variable was also created and coded as continuous. Respondents were asked to indicate which, if any, of the following 15 areas were body regions where they currently experience PP: back, neck, shoulder, elbow, wrist, hand, pelvis, hip, knee, ankle, foot, abdominal area, chest, buttocks, and specified other. "Cumulative pain areas" was the count of indicated areas.

In an attempt to acknowledge and control for possible effects from the utilization of other CAM practices in the past year, a "cumulative CAM usage" variable was created and coded as continuous with a possible range of $0-14$. 
Table 1. Participant Descriptive Statistics

\begin{tabular}{|c|c|c|c|}
\hline Variable & All $(\mathrm{N}=69)$ & $\begin{array}{c}\text { Massage } \\
\text { in past year } \\
\mathrm{n}=36(52.17 \%)\end{array}$ & $\begin{array}{c}\text { No massage } \\
\text { past year } \\
\mathrm{n}=33(47.83 \%)\end{array}$ \\
\hline \multicolumn{4}{|l|}{ Age } \\
\hline Range & $60-92$ & $60-92$ & $60-84$ \\
\hline Mean (SD) & $69.36(7.68)$ & $68.47(8.19)$ & $70.33(7.09)$ \\
\hline \multicolumn{4}{|l|}{ Age group } \\
\hline 60-64 years & $26(37.68 \%)$ & $17(47.22 \%)$ & $9(27.27 \%)$ \\
\hline 65-74 years & $25(36.23 \%)$ & $11(30.56 \%)$ & $14(42.42 \%)$ \\
\hline 75 years and over & $18(26.09 \%)$ & $8(22.22 \%)$ & $10(30.30 \%)$ \\
\hline Gender (female) & $39(56.52 \%)$ & $20(55.56 \%)$ & $19(57.58 \%)$ \\
\hline Race (white) & $64(92.75 \%)$ & $35(97.22 \%)$ & $29(87.88 \%)$ \\
\hline \multicolumn{4}{|l|}{ Mean annual income ${ }^{a}$} \\
\hline Mean (SD) & $65,521(37,299)$ & $79,367(34,615)$ & $50,137(34,540)$ \\
\hline \multicolumn{4}{|l|}{ Years of education ${ }^{a}$} \\
\hline Mean (SD) & $15.22(3.13)$ & $16.47(2.90)$ & $13.85(2.82)$ \\
\hline \multicolumn{4}{|l|}{ Cumulative morbidity } \\
\hline Mean (SD) & $2.39(1.88)$ & $2.11(1.85)$ & $2.70(1.90)$ \\
\hline \multicolumn{4}{|l|}{ Pain descriptors } \\
\hline Reported back pain & $36(52.17 \%)$ & $18(50 \%)$ & $18(54.55 \%)$ \\
\hline Arthritis diagnosis & $48(69.57 \%)$ & $22(61.11 \%)$ & $26(78.79 \%)$ \\
\hline \multicolumn{4}{|l|}{ Cumulative pain areas } \\
\hline Range & $0-14$ & $0-7$ & $0-14$ \\
\hline Mean (SD) & $2.80(2.29)$ & $2.23(1.70)$ & $3.09(2.80)$ \\
\hline \multicolumn{4}{|c|}{ Cumulative CAM usage $^{a}$} \\
\hline Range & $0-7$ & $1-7$ & $0-6$ \\
\hline Mean (SD) & 2.33 (1.59) & $2.94(1.45)$ & 1.67 (1.47) \\
\hline
\end{tabular}

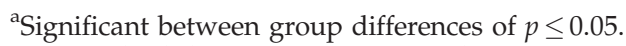

$\mathrm{SD}$, standard deviation; CAM, complementary and alternative medicine.

Respondents were asked to indicate which, if any, of the following CAM therapies or practices they utilized in the past year: meditation, chiropractic, acupuncture, special diets, herbal remedies, copper bracelets, prayer, yoga, T'ai Chi, supplements, hypnosis, magnets, and vitamins. "Cumulative CAM usage" was the count of indicated CAM practices from this select list utilized in the past year.

\section{Analysis}

All analyses were conducted using SAS 9.1 and were conducted in three steps.

Step 1: Continuous variables were summarized with descriptive statistics ( $n$, mean, standard deviation), while categorical variables were described with frequencies and percentages. Chi-squares and analyses of variance were used to determine between-group differences in descriptive statistics based on MTUS. Further descriptive statistics were generated to describe the massage usage characteristics of those who reported receiving MT in the past year.

Step 2: Single variable linear regression was used to determine between-group differences in RAND-36 domain scores based on MTUS.

Step 3: Multiple linear regression (MLR) was used to examine the relationship between MTUS and domains significant in Step 2 by controlling for potentially confounding variables. These potential confounds were identified through Pearson correlation. Variables found to have significant correlation with domain scores were included in the MLR models in addition to MTUS.

\section{Results}

\section{Step 1: Sample Demographics (Tables 1 and 2)}

Table 1 conveys the characteristics of the sample. The age range for the sample was 60-92 (mean: 69.36; SD: 7.68 years). Women comprised $57 \%$ of the sample and a majority $(93 \%)$ was white. Average education for the sample was 15.22 (SD: 3.13 years) and annual income was an average \$65,521 (SD: $\$ 37,299)$. All participants were community-dwelling, with over $95 \%$ owning their residence. A majority (60\%) was retired, and approximately $32 \%$ reported working full- or parttime. Mean annual income and years of education were significantly higher ( $p=0.002$ and $<0.001$, respectively) for those who utilized MT in the past year compared to those who did not indicate MT usage in the past year. Because years of education were highly correlated with income (correlation coefficient $=0.33 ; p=0.012$ ), and given that nearly $20 \%$ of participants were missing income data, years of education were used as a proxy for income. Participants who received MT in the past year also utilized, on average, a significantly higher number of CAM options in the past year.

A majority of the sample (52\%) indicated they experienced $\mathrm{PP}$ in their backs, and almost $70 \%$ reported a diagnosis for arthritis. Participants reported experiencing PP in an average of $2.8(\mathrm{SD}=2.29)$ areas of their bodies. No statistically significant differences across MTUS were found in any of these pain descriptor variables.

Participants who indicated that they had received MT during the past year were asked to describe their massage usage, with several questions including estimating the 
number of MT treatments they had received during their lifetime (Table 2). A range of 2-360 lifetime massages were reported, with a majority of them $(68 \%)$ having received MT for 6 or more years. Most participants received treatment from the same therapist over the past year $(57 \%)$, and only $14 \%$ went to 4 or more different therapists for their treatments over the past year. A majority of MT users reported at least monthly treatment sessions (54\%), with typical treatments lasting at least an hour (54\%).

\section{Step 2: Differences in self-reported health based on MTUS}

Those who received MT in the past year had higher average scores in all nine Rand-36 domains compared to those who did not report receiving MT (Fig. 1). Single-variable linear regressions revealed that average scores for those reporting MT in the past year were 20.11 higher in the physical function domain $(p=0.004), 26.19$ higher in the limitations due to physical function domain $(p=0.005), 14.95$ higher in the bodily pain domain $(p=0.008), 11.86$ higher in the emotional well-being domain $(p=0.004), 24.47$ higher in the limitations due to emotional issues domain ( $p=0.001), 16.76$ higher in the social functioning domain $(p=0.005), 14.27$ higher in the energy/fatigue domain $(p=0.005), 14.28$ higher in the general health domain $(p=0.006)$, and 8.73 higher in the perceived change in health domain $(p=0.051)$ than those

Table 2. Massage Usage Characteristics $(\mathrm{N}=36)$

\begin{tabular}{|c|c|}
\hline Variable & $\mathrm{n}=36$ \\
\hline \multicolumn{2}{|c|}{ Approximate lifetime massages } \\
\hline Range & $2-360$ \\
\hline Mean (SD) & $62.85(78.90)$ \\
\hline Median & 28 \\
\hline Mode & 100 \\
\hline Groups & $\mathrm{n}(\%)$ \\
\hline Fewer than 25 & $16(47.06)$ \\
\hline $25-50$ & $3(8.82)$ \\
\hline $51-99$ & $3(8.82)$ \\
\hline 100 or more & $12(35.29)$ \\
\hline \multicolumn{2}{|l|}{ Massage frequency } \\
\hline 1 or more weekly & $3(8.57)$ \\
\hline 1 or 2 monthly & $16(45.71)$ \\
\hline 2 to 4 per year & $5(14.28)$ \\
\hline Yearly or less & $11(31.43)$ \\
\hline \multicolumn{2}{|l|}{ Years receiving massage } \\
\hline Less than 1 year & $2(5.88)$ \\
\hline $1-5$ years & $9(26.47)$ \\
\hline $6-10$ years & $10(29.41)$ \\
\hline $11-19$ years & $9(26.47)$ \\
\hline 20 or more years & $4(11.76)$ \\
\hline \multicolumn{2}{|c|}{ Number of therapist in last year } \\
\hline 1 & $20(57.14)$ \\
\hline 2 & $9(25.71)$ \\
\hline 3 & $1(2.86)$ \\
\hline 4 or more & $5(14.29)$ \\
\hline \multicolumn{2}{|c|}{ Typical treatment duration } \\
\hline Less than 30 minutes & 0 \\
\hline 30-59 minutes & $12(34.29)$ \\
\hline 60-89 minutes & $19(54.29)$ \\
\hline 90 or more minutes & $4(11.43)$ \\
\hline
\end{tabular}

$\mathrm{SD}$, standard deviation. who did not report MT in the past year (recall that higher scores indicate better health).

\section{Step 3: Multiple linear regressions}

When significant correlations between potentially confounding variables (age, gender, years of education, cumulative morbidity, cumulative pain areas, and cumulative CAM usage) and specific RAND-36 domains were found, the variable was included in that category's regression model. Based on statistically significant Pearson correlations (data not shown), the following MLR models were developed: Model 1-Physical Function (age, cumulative morbidities, education, cumulative pain areas, cumulative CAM usage, and MTUS were included in the model); Model 2-Limitations Due to Physical Issues (age, gender, education, cumulative morbidity, cumulative pain areas, MTUS); Model 3Emotional Well-Being (education, cumulative pain areas, MTUS); Model 4-Limitations Due to Emotional Issues (education, cumulative morbidity, cumulative pain areas, MTUS): Model 5-Energy/Fatigue (age, cumulative morbidity, cumulative pain areas, MTUS); Model 6-Social Functioning (education, cumulative morbidity, cumulative pain areas, MTUS); Model 7-Pain (education, cumulative morbidity, cumulative pain areas, MTUS); and Model 8-General Health (education, cumulative morbidity, cumulative pain areas, MTUS). No variables significantly correlated with the change in perceived health category; therefore, no MLR model was developed to examine that RAND-36 outcome score.

MLR revealed significant differences between mean outcome scores for those who did and did not receive MT for six of the eight domains (Table 3). Specifically, participants who received MT in the past year reported fewer limitations due to physical issues $(p=0.044)$, better emotional well-being $(p=0.007)$, fewer limitations due to emotional issues $(p=0.012)$, higher energy/less fatigue $(p=0.020)$, better social functioning $(p=0.029)$, and better general health $(p=0.043)$, even when controlling for potential confounds. The only RAND-36 domains that MLR did not indicate MTUS to be significantly associated with were physical functioning and pain.

\section{Discussion}

It was hypothesized that differences in demographic characteristics would be found for participants in this study based on MTUS. Participants who utilized MT in the past year had significantly higher incomes, more years of education, and greater cumulative CAM usage than those who did not report massage usage. People with higher incomes are more apt to receive MT and other CAM practices because payment burden for treatments is primarily out-of-pocket. Participants in this study were given the opportunity to report what reasons (from of a list of 12 options) would prevent them from getting massage (data not shown). Although $50 \%$ of those who had received MT in the past year indicated cost would/does prevent them from receiving MT, a significantly higher percentage $(78 \%, p=0.02)$ of those who did not receive MT in the past year indicated cost as a barrier to receiving MT. With the current study having established that there is a relationship between MTUS and self-reported health among older adults with PP, future studies are needed 
RAND-36 Health Scores Across Massage Usage

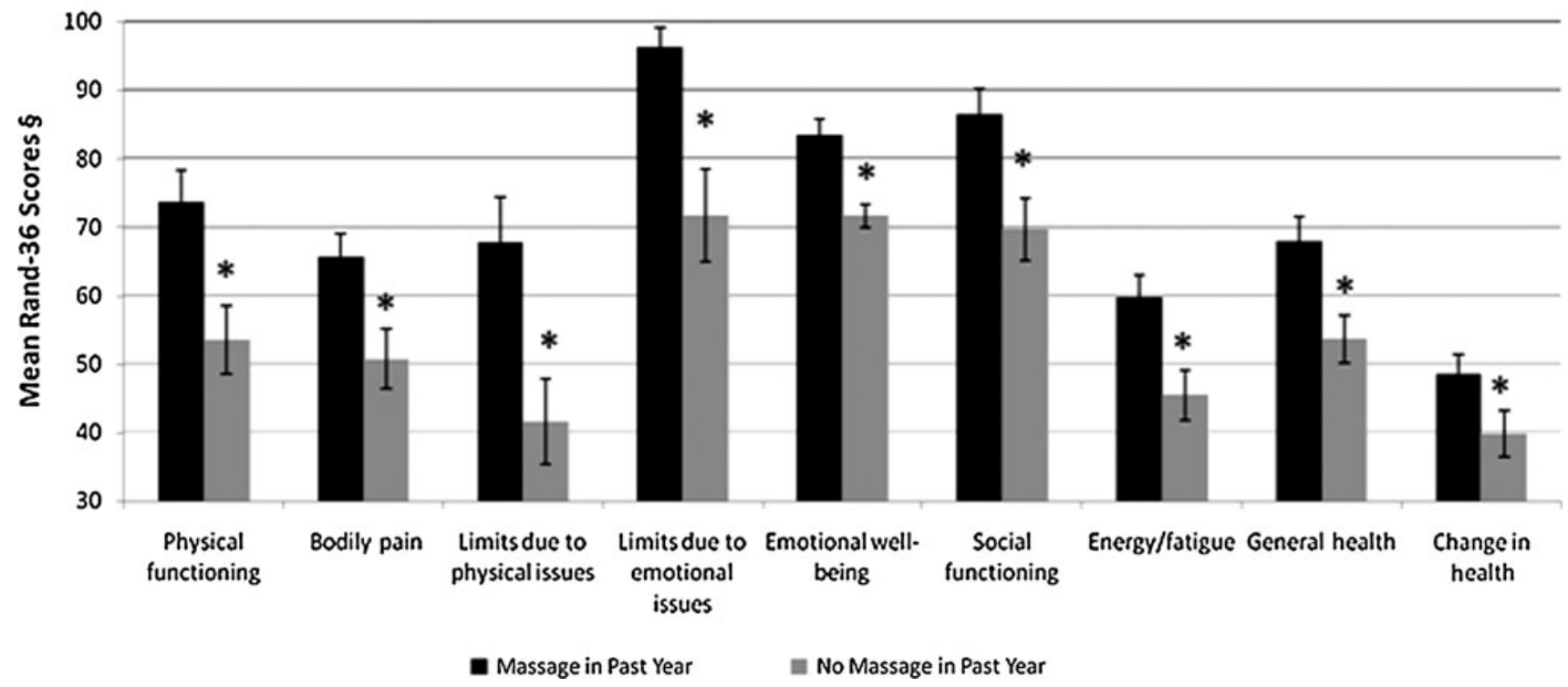

FIG. 1. Graphic representation of RAND-36 scores for users and nonusers of massage therapy. §Higher scores signify better health; *indicates $p \leq 0.05$ between-group difference.

to determine whether there is a causal relationship between these variables in this population. Such future studies may serve as a foundation for advocacy of policy changes that would facilitate older adults receiving massage. Targets of policy change might include Medicare and Medicaid, which could be revised to cover the cost of MT for older adults with PP since cost appears to be a barrier to such treatment.

It is logical to hypothesize that those who utilized MT took better care of themselves in general, support for which is provided by the fact that those who received massage in the past year also utilized significantly more CAM options. However, cumulative CAM usage was only correlated with physical function and did not contribute significantly in the MLR model of physical function developed for this study. This indicates that, overall, amount of CAM usage other than MT does not predict the health and well-being domains examined in the current study, at least among those sampled here. Future studies designed specifically to examine the relationship between other CAM modality usage and health and well-being among older adults with PP may be warranted. Furthermore, participants in the current study were asked about their routine medical care (data not shown). All participants, regardless of MTUS, reported visiting the doctor on either a regular basis or when they experienced a problem. There was no statistically significant difference in routine medical care practices between those reporting and not reporting MT in the past year.

Regarding the second hypothesis, it was found that receiving MT in the past year was associated with higher scores in all nine RAND-36 domains. It was further hypothesized that these differences would be unaffected by potentially confounding factors. While this was the case for six of the eight domains, the physical functioning domain (Model 1) and pain domain (Model 7), scores did not differ based on MTUS. Regarding Model 1, physical function appears to be affected by factors other than MTUS (e.g., in- creased age or cumulative pain areas). However, the lack of between-group differences may indicate that those who received MT in the past year improved their physical function to levels similar to those whose decrements in physical functioning did not affect their quality of life enough for them to seek out an alternative such as MT. This speculation must be evaluated through future longitudinal studies wherein levels of physical functioning are assessed prior to, during, and after MT to determine the effects of MT on physical function over time.

Of particular interest is the lack of difference in the pain domain scores (Model 7), regardless of MTUS, once confounds were added to the MLR model. Utilization of MT in the past year was not associated with lower reports of pain and/or limitations due to pain. The lack of statistical significance for Model 7, coupled with the fact that no significant differences were found across MTUS in any of the pain descriptor variables, might indicate one of two things. First, older adults with PP who received MT in the past year might have had significantly better scores in the six significant domains despite similar pain experiences compared to those who did not receive MT. MT might have better equipped those who utilized such therapy to cope with their pain, as evidenced by the better emotional health reported by that group. Second, the results may indicate that those who utilized MT had experienced worse pain or more areas of pain prior to receiving therapy and that MT reduced their experience of pain to similar levels as those whose pain experience was not severe enough to lead them to attempt MT as a remedy. To determine the veracity of these hypothesized explanations, future research should be conducted using a longitudinal research design to establish the temporal sequence of change in well-being and in report of pain and pain descriptors in relationship to receipt of MT.

While the current study cannot attest to change in participants' reported health over time based on MTUS or the 
Table 3. Multiple Linear Regression Models

\begin{tabular}{|c|c|c|c|}
\hline Domain $\left(\Delta R^{2}\right) /$ predictor & $\begin{array}{l}\text { Parameter } \\
\text { estimate }\end{array}$ & $\begin{array}{c}95 \% \\
\text { Confidence } \\
\text { interval }\end{array}$ & $\mathrm{p}-$ Valu \\
\hline $\begin{array}{l}\text { Model 1-Physical } \\
\text { Function }(0.3922)\end{array}$ & & & 0.001 \\
\hline Intercept & 143.17 & $84.25,202.08$ & $<0.001$ \\
\hline Age & & $2.28,-0.74$ & 0.001 \\
\hline Cumulative & -2.51 & $-5.80,0.79$ & 0.134 \\
\hline Educa & & $-0.02,3.94$ & 0.053 \\
\hline Cumulative & -2.87 & $-5.43,-0.31$ & 0.029 \\
\hline $\begin{array}{l}\text { Cumulative CAM } \\
\text { usage }\end{array}$ & 3.10 & $-0.79,6.99$ & 0.116 \\
\hline MTUS & 4.79 & $-8.98,18.55$ & 0.490 \\
\hline $\begin{array}{c}\text { Model 2-Limitations } \\
\text { Due to Physical } \\
\text { Issues }(0.2862)\end{array}$ & & & 0.001 \\
\hline Intercept & 56 & $66.68,246$ & 0.001 \\
\hline Age & & -2.25 & 0.049 \\
\hline Ge & & -25.004, & .455 \\
\hline Ed & & -3 & 0.949 \\
\hline $\mathrm{Cu}$ & & -9 & .080 \\
\hline $\mathrm{Cu}$ & & -0 & 0.045 \\
\hline MTUS & 19.02 & $0.55,37.49$ & 0.048 \\
\hline $\begin{array}{l}\text { Model 3-Em } \\
\text { Well-Bein }\end{array}$ & & & 0.007 \\
\hline Interce & 7 & 58 & $<0.001$ \\
\hline Ed & & -1 . & 0.748 \\
\hline $\mathrm{Cu}$ & -8 & $-16.15,-$ & 0.042 \\
\hline MT & 12.08 & $3.36,20$ & 0.007 \\
\hline $\begin{array}{l}\text { Model 4-Limitations } \\
\text { Due to Emotional } \\
\text { Issues }(0.2219)\end{array}$ & & & $<0.001$ \\
\hline Inte & & 38 & .001 \\
\hline Ed & & 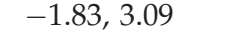 & .610 \\
\hline $\mathrm{Cu}$ & -3 & -7 & 0.091 \\
\hline $\mathrm{Cu}$ & -16 & $-30.65,-$ & 0.023 \\
\hline MTUS & 20.22 & $4.70,35.73$ & 0.012 \\
\hline $\begin{array}{l}\text { Model 5-Energy / } \\
\text { Fatigue }(0.3845)\end{array}$ & & & 0.001 \\
\hline Interc & & & $<0.001$ \\
\hline Age & -0 & $-0.80,0$ & 0.406 \\
\hline Cum & -3.81 & $-6.19,-1$ & 0.002 \\
\hline $\mathrm{Cu}$ & -3 . & $-4.98,-1$ & 0.001 \\
\hline MTL & 9.83 & $1.61,18.06$ & 0.020 \\
\hline $\begin{array}{l}\text { Model 6-Social } \\
\text { Functioning }\end{array}$ & & & $<0001$ \\
\hline Inte & & 14 & 01 \\
\hline Ed & 7 & 1 & 0.939 \\
\hline $\mathrm{Cu}$ & -3.11 & $1,-$ & .030 \\
\hline $\mathrm{Cu}$ & -4.5 & $-6.84,-2$ & $<0.001$ \\
\hline $\mathrm{M}$ & 12.55 & $1.35,23.74$ & 0.029 \\
\hline Model & & & $<0.001$ \\
\hline & & & $<0.001$ \\
\hline $\mathrm{Ed}$ & & 1,2 . & 0.936 \\
\hline $\mathrm{Cu}$ & -3 & $-6.38,-1$ & 0.003 \\
\hline areas & -4.28 & $-6.32,-2.25$ & $<0.001$ \\
\hline MTUS & 8.39 & $-1.65,18.44$ & 0.100 \\
\hline $\begin{array}{l}\text { Model 8-General } \\
\text { Health }(0.3083)\end{array}$ & & & $<0.001$ \\
\hline Inter & 71.85 & $48.82,94.89$ & $<0.001$ \\
\hline Edu & & -1 & 0.935 \\
\hline Cum & -4.26 & $-6.74,-1.78$ & 0.001 \\
\hline ative pain areas & -2.45 & $-4.47,-0.44$ & 0.018 \\
\hline MTUS & 10.23 & $0.32,20.15$ & 0.043 \\
\hline
\end{tabular}

Bolded $p$-values indicate massage therapy usage status (MTUS) significance in the model.

CAM, complementary and alternative medicine. causal nature of the relationship between the variables examined here, the findings do begin an evidence-based discussion regarding the association between MT and health/ quality of life for older adults who experience PP. This study indicates that regardless of increased age, cumulative morbidities, and cumulative pain areas, older adults who experience PP and received MT in the past year reported having significantly better emotional and general health, more energy, and better social functioning than did those older adults with PP who did not receive massage.

\section{Limitations}

Due to the cross-sectional design of the current study, causation regarding MT usage and reported health can be hypothesized but not confirmed. Furthermore, in the current study non-white individuals were under-represented. In addition, because sampling was from the voter registration pool, older adults who were not registered voters in Fayette County at the time of the survey were potentially excluded. However, given that older adults tend to be more politically active (i.e., registered to vote) ${ }^{41}$ the vast majority of persons 60 and older in Fayette County, Kentucky are likely registered voters, thus decreasing the risk of sampling bias. This study is also limited by the lack of information regarding the pain experienced by the older adults in this study. Specifically, neither intensity nor duration of pain was measured, which limits the understanding of the experience of PP represented by this sample. Perhaps the most significant limitation to the current study is the fact that it is based on analysis of data not collected for the specific purpose of addressing the hypotheses evaluated here.

\section{Conclusions}

The current study demonstrated that for older adults experiencing PP, massage is associated with self-report of less limitation due to physical or emotional issues, better emotional health, more energy/less fatigue, better social functioning, and better overall health. Age, education, cumulative morbidities, and number of areas in which participants reported experiencing PP did not affect the association between receipt of massage and better self-reports in those domains, lending support to the idea that perhaps massage was the influential factor.

It is commonly believed and asserted by practitioners and advocates of MT that such therapy improves and supports health and wellness in most, if not all, populations. However, few massage research studies focus specifically on older adults. As a population at higher risk for living with $\mathrm{PP}^{1}{ }^{1}$ older adults stand to benefit from the development of a greater understanding of the extent to which MT may improve quality of life and reduce the impact of their experience of pain.

Because the experience of pain is subjective and unique for everyone, future MT studies would benefit from collecting more detailed information regarding the pain experienced by the older adults who participate. Future studies would also benefit from increased participation from a variety of races, to assess whether non-whites have similar experiences.

As a secondary data analysis study, the current study provides foundational evidence justifying further assessment of the nature of the relationship between MT and the health 
and quality-of-life domains examined in this study. Future studies should employ a longitudinal approach, examining health and well-being domains prior to, during, and after participation in an MT regimen. Such studies should seek to elucidate differences in health domains prior to voluntary participation in MT to determine whether those who seek MT are indeed experiencing worse reported health, as posited here, and perhaps seeking MT as a "last resort" to address their health concerns.

\section{Acknowledgments}

Special thanks are extended to the individuals who participated in this study and the massage clinics that made surveys available to their clients: Lexington Healing Arts Academy, In Touch, Inc., Inner Dimensions, Body Systems Therapeutic Massage, and Stewart Massage Therapy. This study was generously supported by start-up funds awarded by the University of Kentucky to Faika Zanjani, PhD.

\section{Disclosure Statement}

No competing financial interests exist.

\section{References}

1. Thomas E, Peat G, Harris L, et al. The prevalence of pain and pain interference in a general population of older adults: Cross-sectional findings from the North Staffordshire Osteoarthritis Project (NorStOP). Pain 2004;110:361368.

2. Reyes-Gibby CC, Aday L, Cleeland C. Impact of pain on self-rated health in the community-dwelling older adults. Pain 2002;95:75-82.

3. Miller LR, Cano A. Comorbid chronic pain and depression: Who is at risk? J Pain 2009;10:619-627.

4. Schuler M, Njoo N, Hestermann M, et al. Acute and chronic pain in geriatrics: Clinical characteristics of pain and the influence of cognition. Pain Med 2004;5:253-262.

5. Parmelee PA, Smith B, Katz IR. Pain complaints and cognitive status among elderly institution residents. J Am Geriatr Soc 1993;41:517-522.

6. Gibson SJ, Katz B, Corran TM, et al. Pain in older persons. Disabil Rehabil 1994;16:127-139.

7. Pharmacological management of persistent pain in older persons. J Am Geriatr Soc 2009;57:1331-1346.

8. Eisenberg DM, Kessler RC, Van Rompay MI, et al. Perceptions about complementary therapies relative to conventional therapies among adults who use both: Results from a national survey. Ann Intern Med 2001;135:344-351.

9. Astin JA. Why patients use alternative medicine: Results of a national study. JAMA 1998;279:1548-1553.

10. Barnes PM, Powell-Griner E, McFann K, Nahin RL. Complementary and alternative medicine use among adults: United States, 2002. Adv Data 2004;343:1-19.

11. Rossler W, Lauber C, Angst J, et al. The use of complementary and alternative medicine in the general population: Results from a longitudinal community study. Psychol Med 2007;37:73-84.

12. Shmueli A, Shuval J. Are users of complementary and alternative medicine sicker than non-users? Evid Based Complement Alternat Med 2007;4:251-255.

13. Astin JA, Pelletier KR, Marie A, Haskell WL. Complementary and alternative medicine use among elderly persons: One-year analysis of a Blue Shield Medicare supplement. J Gerontol A Biol Sci Med Sci 2000;55:M4-M9.

14. Kaboli PJ, Doebbeling BN, Saag KG, Rosenthal GE. Use of complementary and alternative medicine by older patients with arthritis: A population-based study. Arthritis Rheum 2001;45:398-403.

15. Cheung CK, Wyman JF, Halcon LL. Use of complementary and alternative therapies in community-dwelling older adults. J Altern Complement Med 2007;13:997-1006.

16. Cherkin DC, Sherman KJ, Deyo RA, Shekelle PG. A review of the evidence for the effectiveness, safety, and cost of acupuncture, massage therapy, and spinal manipulation for back pain. Ann Intern Med 2003;138:898-906.

17. Furlan AD, Imamura M, Dryden T, Irvin E. Massage for lowback pain. Cochrane Database Syst Rev 2008;4:CD001929.

18. Moraska A, Chandler C, Edmiston-Schaetzel A, et al. Comparison of a targeted and general massage protocol on strength, function, and symptoms associated with carpal tunnel syndrome: A randomized pilot study. J Altern Complement Med 2008;14:259-267.

19. Field T, Diego M, Hernandez-Reif M, Shea J. Hand arthritis pain is reduced by massage therapy. J Bodywork Movement Ther 2007;11:4.

20. Corbin L. Safety and efficacy of massage therapy for patients with cancer. Cancer Control 2005;12:158-164.

21. Field T, Diego M, Cullen C, et al. Fibromyalgia pain and substance $\mathrm{P}$ decrease and sleep improves after massage therapy. J Clin Rheumatol 2002;8:72-76.

22. Hernandez-Reif M, Field T, Ironson G, et al. Natural killer cells and lymphocytes increase in women with breast cancer following massage therapy. Int J Neurosci 2005;115: 495-510.

23. Sunshine W, Field TM, Quintino O, et al. Fibromyalgia benefits from massage therapy and transcutaneous electrical stimulation. J Clin Rheumatol 1996;2:18-22.

24. Mok E, Woo CP. The effects of slow-stroke back massage on anxiety and shoulder pain in elderly stroke patients. Complement Ther Nurs Midwifery 2004;10:209-216.

25. Carmeli E, Coleman R, Reznick AZ. The biochemistry of aging muscle. Exp Gerontol 2002;37:477-489.

26. Hayflick L. How and why we age. New York: Ballantine Books, 1996.

27. Miesler DW. Geriatric Massage Techniques. Sunrise, FL: Massage Review Publications, Inc., 1990.

28. Nelson D. From the Heart Through the Hands: The Power of Touch in Caregiving. Scotland: Findhorn Press, 2001.

29. Nelson D. Therapeutic Massage in Facility Care: Benefits, Effects and Implementation. Sunrise, Fl: Massage Review Publications, 2004.

30. Rose MK. Comfort Touch: Massage for the Elderly and the Ill. Philadelphia: Lippincott Williams \& Wilkins, 2010.

31. Field T, Hernandez-Reif M, Quintino O, et al. Elder retired volunteers benefit from giving massage therapy to infants. J Appl Gerontol 1998;17:11.

32. Fraser J, Kerr JR. Psychophysiological effects of back massage on elderly institutionalized patients. J Adv Nurs 1993;18:238-245.

33. Sharpe PA, Williams HG, Granner ML, Hussey JR. A randomised study of the effects of massage therapy compared to guided relaxation on well-being and stress perception among older adults. Complement Ther Med 2007;15:157163.

34. Gavrilov LA, Gavrilova NS. Reliability theory of aging and longevity. In: Masoro EJ, Austad SN, eds. Handbook of the 
Biology of Aging. 6 ed. Burlington, MA: Elsevier Academic Press, 2006.

35. Munk N, Zanjani F. Relationship between massage therapy usage and health outcomes in older adults. J Bodywork Movement Ther 2011;15:177-185.

36. Hays RD, Morales LS. The RAND-36 measure of healthrelated quality of life. Ann Med 2001;33:350-357.

37. Hays RD, Sherbourne CD, Mazel RM. The RAND 36-Item Health Survey 1.0. Health Econ 1993;2:217-227.

38. AMTA. 2008 MassageTherapy Industry Fact Sheet. 2007. Online document at: http://amtamassage.org/uploads/ cms/documents/2008IndustryFactSheet.pdf Accessed June 15, 2008.

39. AMTA. 2010 Massage Therapy Industry Fact Sheet. 2010. Online document at: http://amtamassage.org/articles/ 2/PressRelease/detail/2146\#6 Accessed September 1, 2010.

40. Eisenberg DM, Davis RB, Ettner SL, et al. Trends in alternative medicine use in the United States, 1990-1997: Results of a follow-up national survey. JAMA 1998;280: 1569-1575.
41. Eisenberg DM, Kessler RC, Foster C, et al. Unconventional medicine in the United States: Prevalence, costs, and patterns of use. NEJM 1993;328:246-252.

42. Helmick CG, Felson DT, Lawrence RC, et al. Estimates of the prevalence of arthritis and other rheumatic conditions in the United States: Part I. Arthritis Rheum 2008;58:15-25.

43. Reginster JY. The prevalence and burden of arthritis. Rheumatology (Oxf) 2002;41(supp 1):3-6.

44. Bressler HB, Keyes WJ, Rochon PA, Badley E. The prevalence of low back pain in the elderly: A systematic review of the literature. Spine (Phila Pa 1976) 1999;24:1813-1819.

Address correspondence to: Niki Munk, PhD, LMT Graduate Center for Gerontology University of Kentucky 900 South Limestone 304B Wethington Health Sciences Building Lexington, KY 40536

E-mail: Niki.Munk@uky.edu 